\title{
Percepção da comunidade local sobre o turismo no Parque Nacional da Chapada das Mesas, Carolina (MA)
}

\section{Perception of the local community on tourism in the National Park of Chapada das Mesas, Carolina (MA, Brazil)}

Stephanni Gabriella Silva Sudré, Thais Vieira de Souza, Andressa Nogueira de Oliveira, Camilo da Silva Azevedo

RESUMO: O presente estudo dedicou-se a analisar o turismo no Parque Nacional da Chapada das Mesas na perspectiva da comunidade local. E para isso desenvolveu seus objetivos específicos: Identificar a percepção sobre o turismo pela comunidade local e do entorno do PNCM; Entender a relação da comunidade com o turismo no PNCM e Compreender as possibilidades de participação da comunidade no turismo do PNCM. A metodologia utilizada foi pelos fins a pesquisa qualitativa e pelos meios a pesquisa descritiva exploratória. A coleta de dados ocorreu por meio da Pesquisa Bibliográfica direcionada as publicações sobre ecoturismo e Pesquisa Documental nos dados disponíveis do PNCM. A Pesquisa de Campo se deu através da visitação aos integrantes da comunidade na rota dos atrativos Cachoeira do Prata e Cachoeira de São Romão, e através de entrevista semiestruturada com roteiro de entrevista orientado pelos objetivos. Assim, foi possível observar que a comunidade percebe o turismo no PNCM como potencial gerador de renda, porém, são poucas as oportunidades dadas pelo mercado e pela gestão do parque.

PALAVRAS CHAVE: Unidades de Conservação; Ecoturismo; Participação Comunitária; Turismo.

ABSTRACT: The present study focused on analyzing tourism in the Chapada das Mesas National Park from the perspective of the local community. And for that, it developed its specific objectives: Identify the perception about tourism by the local community and the environment of the PNCM; Understand the community's relationship with tourism in PNCM and Understand the possibilities of community participation in PNCM tourism. The methodology used was for qualitative research purposes and by means of descriptive exploratory research. The data collection took place through the Bibliographic Survey directed the publications on ecotourism and Documentary Research in the available data of the PNCM. The Field Survey was given through the visitation to the members of the community in the route of the attractions of Waterfull do Prata and Waterfull de São Romão and will take place through a semi-structured interview with an interview guide guided by the objectives. And it was possible to observe that the community perceives tourism in PNCM as a potential income generator, but there are few opportunities given by the market and the management of the park.

KEYWORDS: Conservation Units; Ecotourism; Community Participation; Tourism. 


\section{Introdução}

As Unidades de Conservação (UC) são espaços que buscam a manutenção das áreas naturais através da gestão da conservação e preservação dos recursos ambientais. E surgiram a partir das reflexões sociais e acadêmicas sobre a importância das garantias da saúde do ambiente natural para a qualidade de vida e desenvolvimento local.

A relação intrínseca com a natureza passou em pouco tempo para uma dinâmica nociva de ciclos de difícil assimilação, e as Unidades de Conservação é uma resposta à crise ambiental e sociocultural. Neste contexto, a busca por Unidade de Conservação para o lazer passou a ser uma alternativa para exercer e valorizar a relação com patrimônio natural e cultural.

O patrimônio natural e cultural são elementos de verdadeira importância para o turismo, e estes elementos fazem parte do patrimônio turístico e são os motivadores da visitação nas Unidades de Conservação. E os parques nacionais são os espaços legalmente constituídos para a o turismo em área natural, e que se por um lado favorece a conscientização ambiental e cultural por outro soma-se as ameaças à integridade deste patrimônio gerada pela presença turística nestes locais.

E o Parque Nacional da Chapada das Mesas (PNCM) apresenta todos aspectos do patrimônio turístico, composta para além da beleza cênica e da conservação dos recursos naturais. $E$ as comunidades locais, no interior e do entorno do parque fazem parte deste patrimônio, e ainda encontram remanescentes como componentes da gestão do turismo e da conservação.

E neste contexto, o trabalho objetivou analisar o turismo no Parque Nacional da Chapada das Mesas na perspectiva da comunidade local, e teve por objetivos específicos, identificar a percepção sobre o turismo pela comunidade local e do entorno do PNCM; entender a relação da comunidade com o turismo no PNCM e compreender as possibilidades de participação da comunidade no turismo do PNCM.

E justifica-se a partir da importância turística do PNCM através do intenso fluxo turístico, participação no mercado ecoturístico, e colabora com respostas aos inúmeros desafios de gestão da visitação, de preservação e conservação ambiental. $\mathrm{E}$ a necessidade de integrar os esforços de respostas científicas para a conservação da biodiversidade através da perspectiva comunitária e conceitual deste segmento, na premissa da sustentabilidade em convergência com os objetivos da UC.

E metodologicamente caracteriza-se pela pesquisa qualitativa e descritivaexploratória, realizadas através de pesquisas bibliográfica e de campo, a partir de consultas a livros e artigos com a temática do turismo em áreas naturais, além de documentos oficiais do Órgão Gestor do PNCM. O campo ocorreu em dois momentos distintos; o primeiro momento foi para o reconhecimento da área de estudo e apresentação e agendamento inicial com os pesquisados e o segundo momento foi com a realização de entrevistas semiestruturada com moradores do interior e entorno da unidade.

E, contudo, o trabalho foi desenvolvido no âmbito do Laboratório de Turismo (LABTUR/UFT), e no contexto da Pesquisa Científica da Universidade Federal do Tocantins em parceria com o Instituto Chico Mendes de Conservação da Biodiversidade (ICMBio) através do Gestor do PNCM. 


\section{Unidades de Conservação e o turismo}

O Sistema Nacional de Unidades de Conservação (SNUC), foi instituído pela Lei $n^{\circ} 9.985$, de 18 de julho de 2000 e propõe estabelecer "critérios e normas para a criação, implantação e gestão das Unidades de Conservação" (BRASIL, 2000)

As Unidades de Conservação são áreas delimitadas pelo Governo Federal, Estadual ou Municipal e passivas de proteção, com objetivos de salvaguardar e patrimônio ecológico e ambiental, garantindo-os para as futuras gerações. Assim, é um espaço territorial e seus recursos ambientais, com objetivos de conservação e limites definidos, sob regime especial de administração, ao qual se aplicam garantias adequadas de proteção (BRASIL, 2000).

As UC's são estratégias que visam a proteção à vida, bem como propiciar momentos de lazer às pessoas. Colaboram com a sobrevivência e proteção dos recursos naturais, lugares de paisagens exuberantes, além da manutenção dos ambientes indispensáveis à vida humana (DICK; DANIELI; ZANINI, 2005, p. 25).

Visando efetivar as políticas públicas de proteção à biodiversidade do Brasil e garantir a manutenção dos ecossistemas, foi promulgada em 28 de agosto de 2007, a Lei ํํ 11.516 que dispõe sobre a criação do ICMBio e suas atribuições (BRASIL, 2007).

Consoante o disposto no artigo $1^{\circ}$ da Lei supramencionada, as atribuições do ICMBio são as seguintes: executar ações da política nacional de Unidades de Conservação da natureza, referentes às atribuições federais relativas à proposição, implantação, gestão, proteção, fiscalização e monitoramento das Unidades de Conservação instituídas pela União; executar as políticas relativas ao uso sustentável dos recursos naturais renováveis e ao apoio ao extrativismo e às populações tradicionais nas Unidades de Conservação de uso sustentável instituídas pela União; fomentar e executar programas de pesquisa, proteção, preservação e conservação da biodiversidade e de educação ambiental; exercer o poder de polícia ambiental para a proteção das Unidades de Conservação instituídas pela União; promover e executar, em articulação com os demais órgãos e entidades envolvidos, programas recreacionais, de uso público e de ecoturismo nas Unidades de Conservação, onde estas atividades sejam permitidas.

Portanto, as Unidades de Conservação federais são geridas pelo Instituto Chico Mendes de Conservação da Biodiversidade - ICMBio, uma autarquia federal do Poder Executivo, vinculada ao Ministério do Meio Ambiente. O ICMBio possui a missão de proteger o patrimônio natural e promover 0 desenvolvimento socioambiental. As UCs possuem um importante papel na conservação da natureza, promovendo o desenvolvimento socioambiental e criando mecanismos de respeito e valorização das comunidades tradicionais (BRASIL, 2007).

Existem dois grupos para a classificação das Unidades de Conservação, cada grupo é composto por categorias distintas, que correspondem aos objetivos para o qual elas foram criadas.

Nos termos do Art. $7^{\circ}$ da Lei ํㅜ 9.985/2000, as unidades que pertencem ao grupo de Proteção Integral têm como objetivo básico "preservar a natureza, sendo admitido apenas o uso indireto dos seus recursos naturais, com exceção dos casos previstos nesta Lei". Já as unidades que pertencem ao grupo de Uso Sustentável têm o objetivo básico de "compatibilizar a conservação da natureza com o uso 
sustentável de parcela dos seus recursos naturais" (BRASIL, 2000). Estas áreas possuem objetivos e determinações de uso para visitação distintas como podemos observar no Quadro 1.

Quadro 1: Categorias de Unidades de Conservação.

\section{Categorias}

Estação Ecológica

Reserva Biológica

Parque Nacional

Monumento Natural

Refúgio de Vida Silvestre

Área de Proteção Ambiental

Área de Relevante Interesse Ecológico

Floresta Nacional

Reserva Extrativista

Reserva de Fauna

Reserva de Desenvolvimento Sustentável

Reserva Particular do Patrimônio Natural

\section{PROTEÇÃO INTEGRAL}

Tipo de visitação

Turismo científico

Turismo pedagógico e científico

Ecoturismo

Ecoturismo e Turismo científico

Ecoturismo e Turismo científico

USO SUSTENTÁVEL

Ecoturismo; Turismo de lazer e científico

Não permitida visitação

Ecoturismo; Turismo de lazer, cultural e científico

Ecoturismo; Turismo de lazer e científico

Turismo científico

Ecoturismo; Turismo de lazer e científico

Ecoturismo; Turismo de lazer, pedagógico e científico

Fonte: BRASIL (2000), adaptado pelos autores (2020).

Source: BRASIL (2000), adapted by the authors (2020).

Para o Ministério do Meio Ambiente (MMA) e o Ministério do Turismo (MTur), é importante que ocorra a visitação nas UCs, pois a visitação funciona como uma estratégia para sensibilizar as pessoas da necessidade de proteger o meio ambiente (BRASIL, 2014).

Nos novos modelos de gestão de Unidades de Conservação, entende-se que "[...] uma das melhores formas de protegê-las é a visitação responsável, com a participação da sociedade, mediante conselhos gestores [...]" (BRASIL, 2014, p.16).

Segundo as Diretrizes para Visitação em Unidades de Conservação, elaborado pelo MMA em 2006, as atividades mais praticadas nas UCs e que possuem maior demanda dos visitantes são: caminhada; mergulho; canoagem e rafting; vôo livre; canionismo e cachoeirismo; montanhismo e escalada; ciclismo; visita a cavernas; observação embarcada; atividades com animais de montaria e acampamento. Vale ressaltar, que estas são apenas algumas das atividades praticadas, e que novas demandas sugiram e estão surgindo, exigindo assim, uma adequação às diretrizes de utilização das UCs.

O turismo tem se destacado por ser uma atividade do terceiro setor da economia que proporciona bem-estar e qualidade de vida a quem o pratica, e por ser fator de desenvolvimento regional e local. Entretanto, ele transpassa o viés econômico.

Zardo (2003, p.7) entende o turismo como "uma complexa interação e interrelação entre os fatores econômicos, sociais, culturais, históricos e ambientais ligados ao deslocamento de pessoas do seu local de residência permanente, desde que não motivados pela remuneração".

A busca por áreas que favorecem esta interação com o meio ambiente conservado tem atraído um grande fluxo de pessoas às áreas protegidas, para o 
desenvolvimento de atividades recreativas e de lazer, sendo que os Parques são cenários ideais para tais práticas.

É possível observar que a beleza cênica somada aos patrimônios históricoculturais das Unidades de Conservação (UCs), geram um poder de atração de turistas e visitantes, apesar de se destinarem inicialmente à conservação ambiental, exercício da educação ambiental, pesquisa científica e contemplação da natureza, são estes fatores que também motivam a visitação (RUSCHMANN, 2005).

As Unidades de Conservações são espaços de grande importância para as atividades turísticas e de visitação, como ocorre nos parques, em busca de lazer, recreação, contemplação ou educação e, quando bem manejada, traz inúmeros benefícios à UC, através da promoção de sua proteção e conservação; benefícios sociais, através da educação ambiental e potencialidade de desenvolvimento regional fomentado pelo turismo.

Os parques nacionais são Unidades de Conservação pertencentes ao grupo de proteção integral e têm como objetivo principal a preservação de ecossistemas naturais de grande relevância ecológica e beleza cênica, possibilitando a realização de pesquisas científicas e o desenvolvimento de atividades de educação e interpretação ambiental, de recreação em contato com a natureza e de turismo ecológico (BRASIL, 2000).

São áreas em que, nos termos da Lei 9.985/2000, "a visitação pública está sujeita às normas e restrições estabelecidas no Plano de Manejo da unidade, às normas estabelecidas pelo órgão responsável por sua administração, e àquelas previstas em regulamento" (BRASIL, 2000).

Assim, Trigo et. al. (2005, p.567) entende que,

A visitação em um parque nacional pode ser compreendida como um conjunto de atividades educacionais, recreativas e de interpretação ambiental realizadas em contato com a natureza, obedecendo às diretrizes dos planos de manejo, nas quais o objetivo é propiciar ao visitante a oportunidade de conhecer, de forma lúdica, os atributos e valores ambientais protegidos por uma Unidade de Conservação.

O Instituto Chico Mendes de Conservação da Biodiversidade (ICMBio) considera que os parques nacionais é a categoria de UC mais conhecida entre a sociedade. De acordo com o relatório Parques Nacionais apenas 20\% dos 297 parques nacionais da época, geraram alguma receita financeira (BRASIL, 2014).

São vários os problemas encontrados nestes destinos, em sua maioria são relativos à falta de investimento, infraestrutura, gestão da visitação e principalmente a falta do Plano de Manejo, que deve orientar as ações dentro de uma UC.

Nas Unidades, o planejamento da visitação é feito por meio do Plano de Uso Público (PUP). Este documento "identifica oportunidades de recreação, conciliando seu uso com a conservação, definindo áreas, atividades permitidas, infraestrutura necessária e delineando trilhas para sua implementação" (WWF-Brasil e IPÊ, 2012, p.216), e deve ser elaborado em consonância com os objetivos de manejo da Unidade. 


\title{
Participação comunitária nas Unidades de Conservação
}

Um dos desafios mais importantes das Unidades de Conservação é estreitar laços com as comunidades que vivem próximas a essas áreas protegidas (BRASIL, 2014). A relação entre a administração de Unidades de Conservação e as populações que vivem no entorno ou dentro dessas áreas tem sido um dos maiores desafios para o conservacionismo.

O fato de as Unidades de Conservação serem reconhecidas como "áreas de proteção" ou "reservas", direcionou a concepção conceitual destes espaços, dando ênfase a face da fiscalização para a conservação ambiental. Nesta dimensão do modo em que as unidades foram sendo formadas, as comunidades ficaram muito ligadas a necessariamente geradores de impactos negativos para as UC's.

A participação das comunidades locais, do entorno e do interior das Unidades de Conservação, foi sendo constituída pela necessidade de identificação da sociedade e principalmente do pertencimento ao meio ambiente. Portanto, a ênfase dos serviços prestados pelos órgãos responsáveis por estas áreas tem tido divulgação apenas pelo controle das pressões humanas, com poucos mecanismos de integração e participação pela comunidade.

A participação comunitária na gestão das UC's está presente em debates sugerindo a integração dos atores sociais nos processos em busca de mitigação das questões socioambientais das unidades. Na perspectiva de Magalhães (2002, apud CARVALHO, 2010, p. 483),

\begin{abstract}
à medida que a comunidade vai se sentindo envolvida, torna-se mais motivada em relação a sua participação no processo de desenvolvimento do turismo, o que pode levar ao surgimento do senso de responsabilidade de ser guardiã dos patrimônios natural, histórico e cultural da localidade.
\end{abstract}

As Unidades de Conservação caracterizam-se como um território construído pelas práticas dos grupos sociais, e ao mesmo tempo, influenciando e transformando essas práticas numa configuração mutável, conflituosa e complexa de relações sociais (COELHO; CUNHA; MONTEIRO, 2009).

\section{Ecoturismo}

A própria conceituação dos segmentos que devem ser desenvolvidos no interior dos parques é contraditórios e passa por avaliações teóricas muito ligadas as intenções mercadológicas.

O segmento mais alinhado às expectativas das UC's é o Ecoturismo, que segundo as Diretrizes para uma Política Nacional de Ecoturismo, que se estabeleceu o marco legal do ecoturismo no Brasil, definiu (BRASIL, 1994, p. 34):

Ecoturismo é um segmento da atividade turística que utiliza, de forma sustentável, o patrimônio natural e cultural, incentiva sua conservação e busca a formação de uma consciência ambientalista através da interpretação do ambiente, promovendo o bem-estar das populações envolvidas. 
Para a Organização Mundial do Turismo (OMT) e o Programa das Nações Unidas para o Meio Ambiente (PNUMA) (2002), o Ecoturismo tem influenciado o desenvolvimento de práticas sustentáveis no âmbito do turismo. No entanto, é necessário ressaltar que este segmento se difere do Turismo Sustentável. E, de acordo com o Ministério do Turismo (2010), a OMT e o PNUMA corroboram afirmando que o ecoturismo é um dos segmentos do turismo, enquanto os princípios que se almejam para o Turismo Sustentável são aplicáveis e devem servir de premissa para todos os tipos de turismo em quaisquer destinos (BRASIL, 2010).

As Diretrizes para uma Política Nacional de Ecoturismo, preconiza assegurar (BRASIL, 1994), à comunidade melhores condições de vida e reais benefícios; ao meio ambiente uma ferramenta que valorize os recursos naturais; à nação: uma fonte de riqueza, divisas e geração de empregos; ao mundo a oportunidade de conhecer e utilizar os patrimônios cultural e natural dos ecossistemas onde convergem a economia e a ecologia, para o conhecimento e uso das gerações futuras.

As ações estabelecidas pelas Diretrizes para uma Política Nacional de Ecoturismo priorizam a participação comunitária, a fim de buscar o engajamento das comunidades localizadas em destinos ecoturísticos, potenciais e existentes, estimulando-as a identificar no ecoturismo uma alternativa econômica viável.

Sobre o ecoturismo e seus conceitos e elementos principais, alguns órgãos internacionais evidenciam a participação comunitária primordialmente (BRASIL, 1994, p.18):

\begin{abstract}
África do Sul: encorajar e promover a participação de comunidades locais nos empreendimentos como atores e gestores atuantes; The International Ecotourism Society (TIES): preparar visitantes para o contato com as comunidades locais; IUCN: envolver comunidades locais, trazendo-Ihes benefícios; SIERRA CLUB: ter seu planejamento de forma a respeitar os direitos, as expectativas e as necessidades de populações tradicionais.
\end{abstract}

O entendimento do Ministério do Turismo (BRASIL, 2009, p. 18) é que o ecoturismo tem como fundamento o bem-estar das populações, com a distribuição dos benefícios resultantes das atividades ecoturísticas, e deve contemplar, principalmente, as comunidades receptoras, de modo a torná-las protagonistas do processo de desenvolvimento da região.

O elemento de diferenciação do Ecoturismo reside no enfoque nas dimensões do Turismo sustentável evidenciado na conservação, interpretação e vivência com a natureza como fator de atratividade (BRASIL, 2009).

O turismo sustentável da base ao ecoturismo, quando impõe o relacionamento das necessidades dos turistas e das regiões receptoras, protegendo e fortalecendo oportunidades para o futuro (OMT, 1999). 


\section{Procedimentos metodológicos}

A escolha do método de pesquisa deve ser definida levando em conta seus objetivos, para que seja possível absorver o entendimento de tudo que ocorra no processo da pesquisa de forma satisfatória.

Este estudo utilizou-se do tipo de pesquisa qualitativa na coleta e análises de dados, que para Oliveira (1997), as pesquisas que utilizam da abordagem qualitativa têm a capacidade de facilitar, de descrever a complexidade de certo problema com maior grau de profundez. Dencker (1998) relata que a pesquisa qualitativa é apropriada para se obter informações de acontecimentos específicos.

A caracterização da pesquisa é a descritiva e exploratória. A pesquisa descritiva busca "identificar, registrar e descrever fatos sem neles interferir" (MENDONÇA et. al., 2008, p. 41), e "o estudo descritivo permite ao pesquisador a obtenção de uma melhor compreensão do comportamento de diversos fatores $e$ elementos que influenciam determinado fenômeno" (OLIVEIRA, 1997, p. 114). Assim, neste estudo utilizou-se da pesquisa descritiva para descrever o fenômeno turismo no Parque Nacional da Chapada das Mesas na visão da comunidade do entorno e interior da Unidade de Conservação.

Dencker (1998), entende que a pesquisa exploratória aperfeiçoa ideias, flexibiliza projetos incorporando o levantamento bibliográfico e entrevistas. Gil (2002), define a pesquisa de caráter exploratório como aquele que tem como objetivo "proporcionar maior familiaridade com o problema, com vistas a torná-lo mais explícito ou a construir hipóteses" GIL, 2002, p. 43).

Para realizar a pesquisa exploratória, o presente estudo seguiu o processo metodológico em três etapas: pesquisa bibliográfica e documental sobre o terma; e pesquisa de campo (coleta de dados) baseada em entrevistas com os moradores.

Lakatos e Marconi (2003, p. 183), indica que a pesquisa bibliográfica envolve "[...] toda bibliografia já tornada pública em relação ao tema de estudo [...]". Nessa perspectiva, Gil (2002) complementa que a pesquisa bibliográfica é aquela desenvolvida com base em material já elaborado, permitindo a quem investiga fazer uma cobertura muito mais ampla.

No presente trabalho, foram utilizadas publicações em bases científicas e livros com ênfase nos temas ligados às questões comunitárias das Unidades de Conservação e o ecoturismo, sendo utilizados produções do próprio ICMBio e do Ministério do Turismo como base conceitual. Foi realizada também, a pesquisa documental, baseada em documentos oficiais, tais como: leis, decretos, plano operativo e notas técnicas. Os documentos oficiais relativos ao Parque Nacional da Chapada das Mesas, utilizados na pesquisa, foram obtidos com a administração da UC.

A pesquisa de campo é uma forma de aproximar o objeto de estudo e o fenômeno a ser investigado, segundo Lakatos e Marconi (2003, p. 186), esta forma de coleta de dados "[...] é aquela utilizada com objetivo de conseguir informações e/ou conhecimentos acerca de um problema, para o qual se procura uma resposta [...]". Para Fachin (2003, p. 133) "a pesquisa de campo assume o papel de observador e explorador, coletando diretamente os dados no local em que surgiram os fenômenos dos estudos". 
Neste trabalho, foi utilizada a entrevista como metodologia de coleta de dados. A entrevista, segundo Vergara (2007), é um artifício onde o pesquisador faz a pergunta e alguém o responde verbalmente.

Para esta entrevista, utilizou-se de roteiro de entrevista orientado, que, para Mello (2006, p. 26), "é aquele que resulta da interação social entre sujeito e pesquisador, é a significação atribuída por eles a determinado objeto de estudo". Na entrevista foi usado um roteiro composto por perguntas abertas que, como pode ser observado no apêndice $A$, é o direcionamento dos questionamentos que objetivavam identificar como o turismo é observado pelos integrantes da comunidade local do Parque Nacional da Chapada das Mesas (PNCM).

A pesquisa de campo foi realizada através de entrevistas aplicadas a uma amostra não probabilística de um dos atores sociais do PNCM, especificamente a comunidade do entorno e do interior da unidade, que compreendem ao corredor turístico ou rota de acesso aos dois atrativos visitados na unidade, utilizada pelas agências de viagem receptiva e g0uias de turismo.

Durante os anos de 2009 e 2011, a equipe do PNCM realizou o levantamento das moradias inseridas dentro da unidade, assim, puderam ser identificadas, aproximadamente, 130 (cento e trinta) famílias, segundo Machado (2011); e Morita e Dias (2013) apud Parola e Ferreira (2018), dispersas em toda a área da Unidade de Conservação.

Entretanto, durante a pesquisa, foram visitados apenas 09 (nove) integrantes da comunidade, entre homens e mulheres, que residiam no entorno e interior da UC Parque Nacional da Chapada das Mesas. Isto porque alguns moradores não estavam presentes em suas residências no dia da entrevista. Além disso, é relevante ressaltar que foram entrevistados apenas moradores que residem à margem da estrada vicinal mais utilizada pelas agências e guias de turismo da região reconhecida rota turística de visitação do PNCM.

As visitas foram realizadas com 0 apoio do ICMBio, pela Unidade Descentralizada em Carolina (MA), e ocorreu em duas etapas. A primeira etapa ocorreu no dia 03/11/2018, para reconhecimento da área a ser estudada e agendamento de uma segunda visita aos moradores. Nesta primeira etapa, foram apresentados a pesquisa e os seus objetivos à comunidade, bem como foi questionado o interesse deles em participar do estudo. Houve o acompanhamento do Gestor do PNCM, o Sr. Deijacy Rego, que intermediou o contato inicial com os atores sociais.

A segunda etapa foi realizada no dia 19/11/2018, com apoio da seguinte equipe de pesquisadores: os acadêmicos Camilo Silva de Azevedo e Andressa Nogueira de Oliveira; a orientadora deste trabalho, a professora Msc. Stephanni Sudré e o Brigadista do Parque, o Sr. Edvan da Rocha Barros. Na segunda etapa, foi aplicada uma entrevista com perguntas abertas a 9 (nove) comunitários. Todos os participantes estiveram à disposição para responder quaisquer perguntas que fossem feitas, ninguém se opôs a responder.

O trabalho foi desenvolvido no âmbito do Laboratório de Turismo, e no contexto da Pesquisa Científica "Gestão do Turismo em Áreas Naturais", registrado no GPU/UFT em parceria com o Instituto Chico Mendes de Conservação da Biodiversidade (ICMBio). A pesquisa foi cadastrada no Sistema Nacional de Gestão 
do Patrimônio Genético e do Conhecimento Tradicional Associado - SisGen sob o cadastro $\mathrm{n}^{\circ} \mathrm{A}$ 033D64.

O acesso à unidade dá-se pelas rodovias BR 230 e BR 010, e por estradas vicinais (MORITA et. al., 2012). Segundo os autores, "As estradas vicinais caracterizam-se pela presença excessiva de areia solta, só podendo ser trafegadas por carros altos e com tração $4 x 4$." (2012, p.10). A área analisada foi escolhida por se tratar de um corredor turístico, pois é a rota de acesso mais utilizada para se chegar aos atrativos turísticos visitados no interior do Parque Nacional da Chapada das Mesas. A Figura 1 destaca $\left(^{*}\right)$ as Cachoeiras do Prata e de São Romão.

Figura 1: Mapa de Localização do Parque Nacional da Chapada das Mesas.

Figure 1: Map od Location of Nacional Park of Chapada das Mesas.

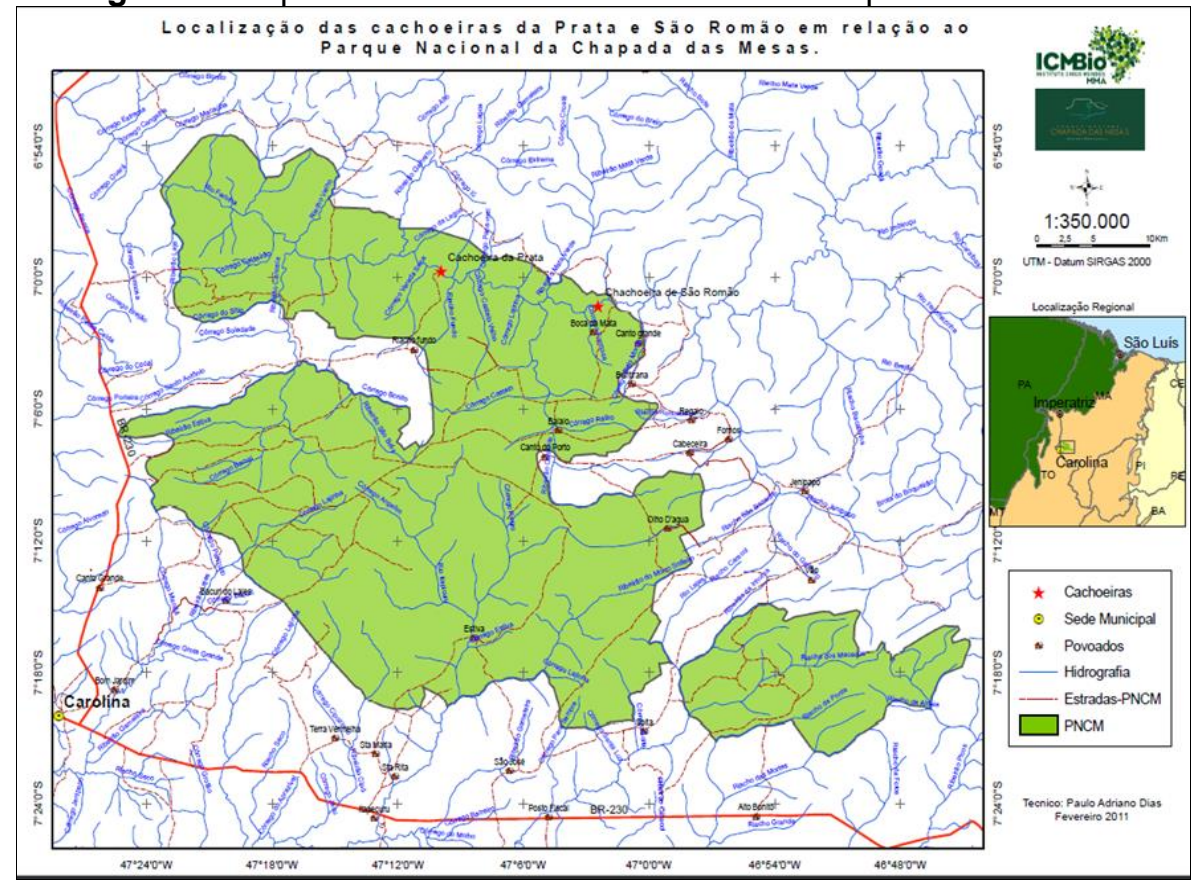

Fonte: Arquivo PNCM DIAS, 2011.

Source: Arquive PNCM DIAS, 2011.

\section{Parque Nacional da Chapada das Mesas}

Criado por demanda da sociedade e instituído pelo Decreto Presidencial s/n de 12/12/2005, o Parque Nacional (PARNA) da Chapada das Mesas é uma Unidade de Conservação federal, do grupo de proteção integral, que abrange uma área de aproximadamente 160.000 ha (cento e sessenta mil hectares) de cerrado, localizada no sudoeste do estado do Maranhão, entre os municípios de Carolina, Estreito e Riachão (DIAS, 2016, 2017).

O PNCM divide-se em duas glebas, sendo que, a gleba maior está inserida nos municípios de Carolina e Estreito, com aproximadamente 140.840 há (cento e quarenta mil, oitocentos e quarenta hectares) e a gleba menor está localizada nos municípios de Carolina e Riachão, com aproximadamente 19.206 há (dezenove mil, duzentos e seis hectares) (BRASIL, 2005).

O objetivo principal do PNCM é a "preservação de ecossistemas naturais de grande relevância ecológica e beleza cênica, possibilitando a realização de pesquisas científicas e o desenvolvimento de atividades de educação e 
interpretação ambiental, de recreação em contato com a natureza e de turismo ecológico", de acordo com o Decreto de 31 de janeiro de 2006, que retificou o art. $1^{\text {}}$ do Decreto de 12 de dezembro de 2005.

A região é conhecida como o Paraíso das Águas, pois possui uma rica hidrografia, conforme aponta Parola e Ferreira (2018, p.6). Segundo as autoras, o PARNA abriga uma grande quantidade de nascentes, rios e riachos, como por exemplo, os rios Farinha e Itapecuru, entre outros.

\begin{abstract}
A região da Chapada das Mesas além de toda beleza cênica formada por cachoeiras, mesetas, morros, serras, riachos cristalinos, vales exuberantes com brejos de buritizais, veredas, toda riqueza em águas superficiais, tem um importantíssimo valor para a manutenção da biodiversidade brasileira uma vez que atua como ecótono entre três biomas: Cerrado, Amazônia e Caatinga (MORITA, et. al., 2012, p.7).
\end{abstract}

Os autores informam ainda, que a região possui esta nomenclatura devido às características dos relevos (morros) de arenito e com superfícies planas, como se fossem pequenas mesetas, muitas delas com inscrições rupestres (MORITA, et. al., 2012).

O Parque possui uma grande demanda de visitação aos atrativos naturais inseridos no interior da unidade, atrativos estes que, já eram explorados antes de sua criação. De acordo com Parola e Ferreira (2018), a visitação ocorre somente em dois atrativos de propriedades privadas, são eles: Cachoeira do Prata e Cachoeira de São Romão. Nelas são prestados serviços básicos para atender o turista, tais como alimentação, taxa de visitação e área de camping.

Cabe informar que o PARNA da Chapada das Mesas, não possui um Plano de Manejo ${ }^{1}$ e/ou Plano de Uso Público, assim, a visitação na unidade ocorre de maneira desordenada e sem a fiscalização direta do ICMBio (PAROLA; FERREIRA, 2018).

O Parque está inserido em uma região com um enorme potencial e vocação turística, isso agrega valor ao destino Chapada das Mesas. O mercado do turismo em Carolina (MA), Estreito (MA) e Riachão (MA) é um forte dado, principalmente ao PARNA da Chapada da Mesas, como indicador observa-se as Agências de Turismo em Carolina (MA) cadastradas no Cadastur no Ministério do Turismo (2018), que chegam ao somatório de 20 (vinte) agências.

\title{
Percepção da comunidade sobre o turismo
}

Carvalho (2010, p.472) cita que "a percepção dos moradores sobre o turismo é necessária para compreender como eles vêem (sic) a atividade, e como estão inseridos na mesma". Logo, torna-se essencial conhecer a visão das comunidades receptoras, porque, afinal, serão elas as que terão maiores impactos com esta atividade.

Os resultados obtidos com base nas entrevistas com a comunidade do entorno e interior do Parque Nacional da Chapadas das Mesas, revelam que os 
moradores residem na região há muitos anos, o mais recente reside há aproximadamente 13 anos, mas alguns moram no lugar desde a infância. Isso nos mostra que, antes mesmo da criação do parque nacional, essas comunidades já estavam instaladas na região, possuindo um forte vínculo de pertencimento com o local, principalmente no que diz respeito às atividades desenvolvidas por eles, como a criação de animais e a agricultura familiar.

E evidenciam que toda atividade do parque seja ela de uso dos espaços ou recursos não pode ignorar a existência dos moradores, e de todo sua produção de tecnologia social e conhecimento local. E quando os moradores falam sobre que mudanças ocorreram em suas vidas ao longo dos anos, e eles reconhecem a criação do parque a mudança principal, e que a criação do parque trouxe algumas modificações no modo de vida.

Conforme indica a moradora 3 (dados da pesquisa, 2018): "Só não é melhor porque o povo não pode botar roça [...]. E a gente tem que viver da roça, porque se não for viver da roça, não tem como." Demonstrando a ausência da gestão da Unidade de Conservação e dos agentes públicos e de planejamento do turismo local em apresentar alternativas de renda para a comunidade. O que nos faz lembrar do turismo como forma de iniciar esta busca de novas fontes de renda e todo seu potencial de mudança ligados a conservação ambiental.

Outra mudança significativa para os entrevistados, diz respeito à energia elétrica, os comunitários acreditam que após a criação do Parque, a população foi impedida de ser beneficiada com o direito básico de energia elétrica. No entanto, apesar da gestão da unidade não se opor à instalação de redes de eletrificação no interior da unidade, exige que sejam seguidas as normativas vigentes para 0 licenciamento ambiental.

No entanto, foi notório o descontentamento da comunidade em relação à infraestrutura básica para receber o visitante. Percebe-se isso na fala do morador 6 (dados da pesquisa, 2018), quando questionado se ele gostaria de receber turistas em sua casa: "Gostaria mais ainda se a gente tivesse mais condições para receber, mas a gente sem energia aqui a gente fica difícil."

E ainda é importante lembrar que o turismo independe de infraestrutura como a energia elétrica, e se apropria de forma devida das oportunidades que a rusticidade de uma região pode apresentar. Com meios de hospedagem, alimentação e atividades de visitação que favorecem este ambiente de maior interação com a natureza.

Em Unidade de Conservação do grupo de proteção integral, a qual fazem parte os parques nacionais, é permite o uso indireto dos recursos. Logo, a atividade ecoturística pode ser desenvolvida nessas áreas (BRASIL, 2000).

Os turistas visitam o PNCM por meio das agências de receptivo e guias locais, que trabalham de maneira independente, haja visto que a visitação ocorre em áreas ainda não indenizadas (BRASIL, 2018), ou não utilizam serviços de guiamento.

Essas agências muitas não privilegiam os moradores como força de trabalho e como local de visitação, ficando evidente que o setor turístico organizado não possui relação direta com a comunidade, uma vez que, de acordo com os moradores 3/4/7/8, as agências quase não param em suas casas. 
Apesar disso, a comunidade consegue identificar uma ou duas agências que, sempre que possível, adquirem seus produtos, possibilitando assim, a divulgação da fabricação dos óleos, azeites e doces entre os turistas. E reconhecem que por esforço pessoal de um condutor de turismo que conhecem o morador e sempre para quando pode na casa dele.

Os poucos moradores que recebem turistas, dizem que os recebem com muita satisfação e alegria, mas afirmam que gostariam de participar mais do turismo que é desenvolvido no parque. Eles confessaram ter o interesse de receber o turista em suas residências e, caso necessário, poderiam hospedá-los também. Pois, de acordo com o morador 5 (dados da pesquisa, 2018), os turistas: "querem conhecer a maneira da gente viver." Assim, é possível identificar a aceitação dos moradores em relação ao desenvolvimento desta atividade, o que influenciará na hospitalidade para com o visitante.

E, portanto, apensar de apresentar várias alternativas como potencial turístico e de hospitalidade os moradores nunca foram provocados e inseridos em ações efetivas de gestão da visitação.

De acordo com as Diretrizes para uma Política Nacional de Ecoturismo (BRASIL,1994), a comunidade local deve ser envolvida e ter participação atuante nos destinos de onde se desenvolve o ecoturismo. Pois muito além de oferecer benefícios econômicos, o ecoturismo deve oferecer melhores condições de vida.

No parque, apenas dois atrativos são explorados pelo turismo. Logo, os proprietários destes atrativos são os que possuem uma relação direta com o turismo, pois oferecem serviços de alimentação, taxa de visitação, área de camping, equipamentos para a prática de esportes etc. É importante ressaltar que esses atrativos compram algumas matérias-primas das refeições oferecidas ao turista, com a comunidade local, como afirma o morador 7 (dados da pesquisa, 2018): "Muitas coisas a gente já compra aqui na região, como frango, farinha e doces."

Os proprietários dos atrativos vendem em seus estabelecimentos, os doces produzidos pela própria comunidade. Isso contribui com a renda de diversas famílias do parque, pois de acordo com o morador 7 (dados da pesquisa, 2018): "já tá começando a gerar emprego pro povo da região. A partir do momento que você começa a consumir na região, aí o negócio muda." Esse dado nos mostra que, apesar de nem todos os moradores estarem envolvidos diretamente com o turismo, ele é gerador de renda para a comunidade local.

Os moradores que não possuem relação direta com o turismo, informaram que gostariam e poderiam oferecer ao turista alimentos cultivados e produzidos por eles mesmos, inclusive utilizando as frutas da região. São exemplos: azeites, óleo de coco, doce de buriti, galinha caipira, requeijão, gergelim, amendoim, castanha de caju, caldo de cana, farinha, entre outros. Podem oferecer ainda artesanatos com palha de coco: abanos, cofos e cabaças. Mas, a princípio não é uma tarefa fácil, visto que, de acordo com a moradora 3 (dados da pesquisa, 2018): "aqui é mais ruim pra gente colocar alguma coisa pra".

Quando foram questionados se teriam interesse em participar de cursos e/ou capacitações relacionadas ao turismo, todos disseram que sim, e que gostariam de aprender mais. Chegaram a sugerir quais cursos teriam interesse, sendo que foi preferência da maioria participar de cursos de culinária e artesanato. 
O ICMBio realiza reuniões comunitárias anualmente no interior e entorno da unidade, essa é uma estratégia de gestão participativa. Os moradores relatam que a gestão da UC sempre os convida, porém, não são todos os que participam. Muitos chegaram a participar das primeiras reuniões realizadas, hoje, não participam mais. Essa informação é preocupante, pois, essas reuniões servem justamente para que a voz da comunidade seja ouvida, e a ausência dos comunitários impede que assuntos relevantes, como o turismo, sejam discutidos. A participação comunitária na gestão da UC é imprescindível para que os conflitos socioambientais sejam minimizados.

\section{Considerações finais}

As Unidades de Conservação têm como função salvaguardar o patrimônio ambiental e natural do planeta. Os parques nacionais são unidades do grupo de proteção integral, e por isso, a legislação prevê que não deve haver moradores dentro de seus limites, mas a regularização fundiária dessas áreas é complicada e cabe ao Poder Público realizar a indenização/desapropriação dos imóveis particulares.

Nesse contexto, cabe ao ICMBio administrar os conflitos entre os interesses da UC's e as comunidades que residem no interior e entorno delas. E este fator é determinante na percepção sobre o turismo no PNCM como um fato distante do seu cotidiano e de difícil adesão pela forma que vem sendo realizada através de empresas de turismo que detém maior força política e de articulação com a gestão do parque.

A pesquisa evidenciou que, a comunidade do Parque Nacional da Chapada das Mesas tem consciência de que o turismo é uma realidade local, e que pode participar do planejamento turístico, porém apenas poucos moradores participam e são, de fato, beneficiados com essa atividade. Ressalta-se o quão importante e necessário é, que haja um planejamento mais participativo.

Incluir a comunidade receptora nas atividades relacionadas ao turismo é uma das premissas do segmento ecoturístico e condição de desenvolvimento do turismo em parques nacionais. E a comunidade apresentou uma variedade de formas e opções de produção e serviços passiveis de visitação e comercialização, sendo mais diferenciado ligados as tecnologias sociais para a hospitalidade.

Cabe ao Poder Público e às agências de receptivo, que operam no PARNA de forma independente, criarem mecanismos de participação e valorização da comunidade local. Ainda, é essencial que seja despertado um senso de empreendedorismo nos moradores, a fim de capacitá-los e prepará-los para receber o turista.

Nesse fato de não possuírem energia elétrica em suas, pode ser um fator que não limita atividade turística, visto que existem muitos visitantes que preferem desconectar-se de toda e qualquer tecnologia e conectar-se com a natureza, como ela realmente é, e conhecer um estilo de vida mais rústico a perspectiva, as UC's tornaram-se aliadas à proteção da natureza.

Considera-se, portanto, os moradores do interior e do entorno do Parque Nacional da Chapada das Mesas, o principal potencial de desenvolvimento do turismo na região, pois são elementos chave tanto na conservação quanto como diferencial competitivo do turismo na região. O fato de não possuírem energia elétrica em suas, pode ser um fator que limita a atividade turística ou não, visto que 
existem muitos visitantes que preferem desconectar-se de toda e qualquer tecnologia e conectar-se com a natureza, como ela realmente é, e conhecer um estilo de vida mais rústico

Para este trabalho, sugere-se que sejam desenvolvidos projetos em parceria com o curso superior de Gestão de Turismo, da Universidade Federal do Tocantins (UFT), em Araguaína (TO), para colaborarem com a o processo de inserção da comunidade no planejamento e gestão da visitação, e ainda criar mecanismos de participação mais alinhados a capacidade de participação da comunidade e com a dinâmica de vida dos moradores. Sugere-se ainda a formação de grupos de pesquisa e atividades que possam colaborar com a criação de um roteiro turístico gerido e organizado pelos moradores tendo o modo de vida e a produção familiar como atrativos. E por fim, ações de educação ambiental com os moradores do parque.

\section{Referências}

BRASIL, Diretrizes para uma política nacional de ecoturismo. Brasília: EMBRATUR, 1994.

BRASIL, Ministério do Meio Ambiente. Relatório Parametrizado - Unidades de Conservação. 2018. Disponível em: http://sistemas.mma.gov.br/cnuc/index .php?ido=relatorioparametrizado.exibeRelatorio\&relatorioPadrao=true\&idUc=272. Acesso em: 25/10/2018.

BRASIL. Decreto $s / n$, de 12 de dezembro de 2005. Cria o Parque Nacional da Chapada das Mesas, nos Municípios de Carolina, Riachão e Estreito, no Estado do Maranhão, e dá outras providências. Brasília, 2005.

BRASIL. Decreto s/n, de 31 de janeiro de 2006. Altera o art. $1^{\circ}$ do Decreto de 12 de dezembro de 2005, que cria o Parque Nacional da Chapada das Mesas, nos Municípios de Carolina, Riachão e Estreito, no Estado do Maranhão. Brasília, 2006.

BRASIL. Lei no 11.516, de 28 de agosto de 2007. Dispõe sobre a criação do Instituto Chico Mendes de Conservação da Biodiversidade. Brasília, 2007.

BRASIL. Lei no 9.985, de 18 de julho de 2000. Regulamenta o art. 225, § 1丷, incisos I, II, III e VII da Constituição Federal, institui o Sistema Nacional de Unidades de Conservação e dá outras providências. Brasília, 2000.

BRASIL. Ministério do Meio Ambiente. Secretaria de Biodiversidade e Florestas. Diretoria de Áreas Protegidas. Diretrizes para Visitação em Unidades de Conservação. Brasília: Ministério do Meio Ambiente, 2006. Disponível em: http://www.mma.gov.br/estruturas/ascom boletins/ arquivos/livro.pdf. Acesso em: 22/10/2018.

BRASIL. Ministério do Turismo. Ecoturismo: orientações básicas. Ministério do Turismo, Secretaria Nacional de Políticas de Turismo, Departamento de Estruturação, Articulação e Ordenamento Turístico, Coordenação Geral de Segmentação. 2.ed. Brasília: Ministério do Turismo, 2010.

BRASIL. Ministério do Turismo. PNT em Ação. Ações de gestão do conhecimento para o aprimoramento da política nacional de turismo. Parques Nacionais. Apêndice D. Março, 2014. Disponível em: Acesso em: http://www.turismo.gov.br/images/pdf/2.1PARQUES NACIONAIS.pdf. Disponível em 22/10/2018. Acesso em 20/10/2018. 
BRASIL. SNUC - Sistema Nacional de Unidades de Conservação. Ministério do Meio Ambiente. 7.ed. Brasília: MMA, 2007.

BRASIL. ICMBIO. PNCM - PLANO OPERATIVO DE MANEJO INTEGRADO DO FOGO 2017. Instituto Chico Mendes de Conservação da Biodiversidade. Parque Nacional da Chapada das Mesas. Carolina, 2017.

CARVALHO, S.M.S. A percepção do Turismo por Parte da Comunidade Local e dos Turistas no Município de Cajueiro da Praia - PI. Revista Turismo em Análise. Vol. 21, n. 3, dezembro, 2010.

COELHO, M.C.N; CUNHA, L.H; MONTEIRO, M.A. Unidades de Conservação: populações, recursos e territórios. Abordagens da Geografia e da Ecologia Política. In: GUERRA, A.J.T; COELHO, M.C.N. (orgs). Unidades de Conservação: abordagens e características geográficas. Rio de Janeiro: Bertrand Brasil, 2009. 67-111.

DENCKER, A.F.M.. Métodos e técnicas de pesquisa em turismo. 7. Ed. São Paulo: Futura, 1998.

DIAS, P.A. NOTA TÉCNICA 001/2016-PNCM. Instituto Chico Mendes de Conservação da Biodiversidade. Parque Nacional da Chapada das Mesas. Carolina, 2016.

DICK, E.; DANIELI, M.A.; ZANINI, A.M. (Orgs.). Gestão participativa em Unidades de Conservação: uma experiência na Mata Atlântica. 1. Ed. Rio do Sul, SC: APREMAVI, 2012.

FACHIN, O. Fundamentos de metodologia científica. 4. Ed. São Paulo: Saraiva, 2003.

GIL, A.C. Como elaborar projetos de pesquisa. 4. ed. São Paulo: Atlas, 2002.

LAKATOS, E.M.; MARCONI, M.A. Fundamentos de metodologia científica. 5.ed. São Paulo: Atlas, 2003.

MELLO, H.P. Turismo e Poder Público: interdependências e convergências. 2006. 50 f. Trabalho de Conclusão de Curso (Graduação em Turismo)- Curso Bacharelado em Turismo, do Estado de Mato Grosso, Nova Xavantina/ MT, 2006.

MENDONÇA, A.F.; ROCHA, C.R.R.; PRUDENTE, H.N. Trabalhos acadêmicos: planejamento, execução e avaliação. Goiânia: Faculdades Alves Faria, 2008.

MORITA, J.P.; MACHADO, LM.F.; DIAS, P.A. Plano de Proteção Anual do Parque Nacional da Chapada das Mesas, 2012. Instituto Chico Mendes de Conservação da Biodiversidade. Parque Nacional da Chapada das Mesas. Carolina, fev.2012.

OLIVEIRA, S.L. Tratado de metodologia científica: projeto de pesquisa, TGI, TCC, monografias, dissertações e teses. Pioneira Thomson Learning, 2001

OMT. Organização Mundial do Turismo. Código Mundial de Ética do Turismo. Santiago do Chile: OMT, 1999.

OMT. Organização Mundial do Turismo. Programa de Meio Ambiente das Nações Unidas (PNUMA). Declaração de Ecoturismo de Quebec. Quebec - Canadá: OMT; UNEP, 2002.

PAROLA, C.M.; FERREIRA, L.M. Caracterização do Parque Nacional da Chapada das Mesas. Instituto Chico Mendes de Conservação da Biodiversidade (ICMBio). Brasília, junho de 2018. 
PINTO, A.C.B. Turismo e meio ambiente: Aspectos jurídicos. Campinas, SP: Papirus, 1998, 7. ed., 2006.

RUSCHMANN, D.V.M. Turismo e planejamento sustentável: A proteção do meio ambiente. Campinas, SP: Papirus, 1997.12 ${ }^{\mathrm{a}} \mathrm{Ed}(2005)$. Coleção turismo.

TRIGO, L.G.G.; NETTO, A.P.; ADRILGUE, M., Carvalho; PIRES, P.S. Análises regionais e globais do turismo brasileiro. São Paulo: Roca. 2005

VERGARA, S.C. Projetos e relatórios de pesquisa em administração. São Paulo: Atlas, 2007.

WWF-Brasil/IPÊ - Instituto de PesquisasEcológicas (sic). Org.: Maria Olatz Cases. Gestão de Unidades de Conservação: compartilhando uma experiência de capacitação. WWF. Brasília, 2012. Disponível em: http://www.egov.ufsc.br/portal/conteudo/uso-p\%C3\%BAblico-em-unidades-deconserva\%C3\%A7\%C3\%A3o-federais-apontamentos-sobre-modalidades-de-delega \%C3\%A7\%C3\%A3o pag. Acesso em 14/11/2018.

ZARDO, E.F. Marketing aplicado ao turismo: ferramentas de marketing para empresas de turismo e destinos turísticos. São Paulo: Roca, 2003.

\section{Nota:}

${ }^{1}$ Documento em fase de elaboração, de acordo com sítio do ICMBio, 2017.

Stephanni Gabriella Silva Sudré: Universidade Federal do Tocantins, TO, Brasil. E-mail: stephanni_@uft.edu.br

Link para o currículo Lattes: http://lattes.cnpq.br/8872671577638597

Andressa Nogueira de Oliveira: Universidade Federal do Tocantins, TO, Brasil. E-mail: andressa.nogueira.uft@gmail.com Link para o currículo Lattes: http://lattes.cnpq.br/5877491226214347

Camilo da Silva Azevedo: Universidade Federal do Tocantins, TO, Brasil. E-mail:kmilo.azevedo@gmail.com Link para o currículo Lattes: http://lattes.cnpq.br/7858334018973802

Thais Vieira de Souza: Instituto Chico Mendes de Biodiversidade, MA, Brasil. E-mail: thais.vs12@hotmail.com Link para o currículo Lattes: http://lattes.cnpq.br/5337460481764055

Data de submissão: 28 de fevereiro de 2020

Data de recebimento de correções: 03 de abril de 2020

Data do aceite: 03 de abril de 2020

Avaliado anonimamente 